Marquette University

e-Publications@Marquette

College of Education Faculty Research and

Publications

Education, College of

7-1-1996

\title{
Testing Models of Counselor Development With a Measure of Counseling Self-Efficacy
}

Timothy Melchert

Marquette University, timothy.melchert@marquette.edu

Victoria L. Hays

University of Michigan

Lynn M. Wiljanen

Colorado State University

Ann K. Kolocek

Accepted version. Journal of Counseling \& Development, Vol. 74, No. 6 (July/August 1996): 640-644.

Permalink. (C) 1996 Wiley-Blackwell. Used with permission.

Timothy P. Melchert was affiliated with Texas Tech University at the time of publication. 
Marquette University

e-Publications@Marquette

\title{
Education Faculty Research and Publications/College of Education
}

This paper is NOT THE PUBLISHED VERSION; but the author's final, peer-reviewed manuscript. The published version may be accessed by following the link in th citation below.

Journal of Counseling \& Development, Vol. 74, No. 6 (July/August 1996): 640-644. DOI. This article is (C) Wiley-Blackwell and permission has been granted for this version to appear in $\underline{\text { e- }}$ Publications@Marquette. Wiley-Blackwell does not grant permission for this article to be further copied/distributed or hosted elsewhere without the express permission from Wiley-Blackwell.

\section{Testing Models of Counselor Development with a Measure of Counseling Self-Efficacy}

\author{
Timothy P. Melchert \\ Department of Psychology at Texas Tech University \\ Victoria L. Hays \\ University of Michigan Counseling and Psychological Services \\ Lynn M. Wiljanen \\ Career Center at Colorado State University \\ Ann K. Kolocek \\ Beaver Dam, Wisconsin
}

\begin{abstract}
Models of counselor development have become very popular, but empirical research has found differences primarily between beginning graduate students and doctoral interns. In the research described here, a counseling self-efficacy instrument was developed and was used to test hypotheses based on self-efficacy theory and models of counselor development, both of which would make similar predictions about increases in counseling self-efficacy resulting from clinical training and experience.
\end{abstract}


The findings include strong reliability and validity evidence for the instrument and several significantly different groups of participants that correspond roughly to the groups hypothesized in stage models of counselor development.

As Holloway (1987) observed, developmental models of counselor training and supervision have become the zeitgeist in supervision theory and research. At least nine of these models have been presented (Blocher, 1983; Fleming, 1953; Grater, 1985; Hess, 1987; Hogan, 1964; Littrell, Lee-Borden, \& Lorenz, 1979; Loganbill, Hardy, \& Delworth, 1982; Stoltenberg, 1981; Stoltenberg \& Delworth, 1987). The models of Grater, Hess, Hogan, Littrell et al., Stoltenberg, and Stoltenberg and Delworth all include four stages of development, ranging from beginning trainee to "master psychologist" (Hogan, 1964, p. 139). The Blocher, Fleming, and Loganbill et al. models do not include developmental stages, but they also focus on the process of developing competence and an identity as a therapist.

Although these models are very appealing intuitively, they have not received consistent empirical support (Borders, 1989; Russell \& Petrie, 1994). For example, Holloway (1987) and Stoltenberg and Delworth (1988) have noted that the predominant finding of research investigating counselor development has been that differences exist only between beginning graduate students and doctoral interns (e.g., Heppner \& Roehlke, 1984; Larson et al., 1992; Miars et al., 1983; Reising \& Daniels, 1983; Tracey, Hays, Malone, \& Herman, 1988; Wiley \& Ray, 1986; Worthington, 1984; Worthington \& Stem, 1985). Therefore, the research project described in this article was designed to examine change in counselors across a broad range of training and experience from the perspective of self-efficacy theory.

One of the major approaches to investigating the process of gaining competence and self-confidence in particular domains of behavior has been self-efficacy theory (Bandura, 1977, 1982, 1986, 1989).

Bandura posited that successful performance of a behavior requires not only knowledge and skills but also beliefs that one has the ability to perform the behaviors required to produce particular outcomes (i.e., efficacy expectations) and expectations that given behaviors will in fact lead to particular outcomes (i.e., outcome expectations). Bandura (1977) theorized that self-efficacy is acquired through four sources (listed in order of descending impact): (a) enactive mastery (i.e., successful performance accomplishments); (b) vicarious learning; (c) verbal persuasion (e.g., support and encouragement); and (d) reductions in emotional arousal (resulting from, for example, observing models). The theory would predict, therefore, that counselors develop increased confidence in their professional abilities as they gain clinical training and experience, which in turn enhances their ability to perform counseling activities. The prediction that counseling self-efficacy is associated with training and experience has received some empirical support (see later) and has also been associated with client outcome: In their review of psychotherapy outcome research, Orlinsky and Howard (1986) found that in two thirds of the research results, client outcome was positively related to therapist self-confidence, whereas therapist "unsureness" was never positively related to outcome.

Five studies have applied self-efficacy theory to the examination of the professional development of counselors, and all have found results that are consistent with the theory. One of these studies (Johnson, Baker, Kopala, Kiselica, \& Thompson, 1989) found that counseling self-efficacy increased over the course of a master's-level prepracticum in counseling, and two other studies found that higher 
counseling self-efficacy was associated with greater clinical experience: Sipps, Sugden, and Favier (1988) found that third- and fourth-year graduate students had higher self-efficacy scores than firstand second-year students, and Larson et al. (1992) found that beginning practicum students had significantly lower scores than master's-level counselors and professional psychologists. (Friedlander and Snyder [1983] found differences in counseling self-efficacy among beginning master's-level students, doctoral students, and interns that seem to be significant, but no test for differences between the groups was reported.)

Three studies have examined the relationship between counseling self-efficacy and other counselor characteristics. In their study of trainee expectations for supervision, Friedlander and Snyder (1983) found that low self-efficacy trainees expected supervisors to demonstrate more expertise and be more evaluative, whereas high self-efficacy trainees expected their supervisors to be more likable and supportive. Friedlander, Keller, Peca-Baker, and Olk (1986) investigated the effects of supervisorsupervisee conflicts on anxiety and performance in counselor trainees and found that counseling selfefficacy was inversely related to anxiety level. Although level of anxiety was also inversely related to performance, no significant relationship between self-efficacy and clinical performance was found in this study. Sipps et al. (1988) examined the relationship among training level, counseling self-efficacy, and difficulty of counseling response type (i.e., from minimal responses, directives, questions, complex responses, to self-disclosures) and found an inverse relationship between difficulty of response type and counselor self-efficacy.

Although none of the five studies summarized earlier obtained results inconsistent with developmental models of training and supervision, none found more than two significantly different groups of counseling self-efficacy scores. The lack of research support for more than two different counselor groups draws into question the validity of these models, most of which have hypothesized four levels of professional development. Therefore, unlike many previous studies, the sample used in this research included participants representing the full range of hypothesized counselor development from beginning counselor trainees through licensed professional psychologists. Previous instruments for measuring counseling self-efficacy were not used in this study because they were intended for use with students only: The Self-Efficacy Inventory (Friedlander \& Snyder, 1983) includes an assessment of confidence in one's ability to complete academic program requirements, and the Counseling SelfEfficacy Scale (Johnson et at., 1989) was designed for use with beginning trainees only. A third instrument, the Counseling Self-Estimate Inventory (Larson et al., 1992), could not be used because it was published after the data for this study had been collected. Therefore, we developed a new counseling self-efficacy instrument for use in this study. The hypotheses tested address the validity of both self-efficacy theory as it relates to counseling and models of counselor and therapist development. We predicted that self-efficacy for performing counseling increases as professional training and experience are acquired.

\section{METHOD}

\section{Sample}

The participant sample consisted of students enrolled in courses in a department of counseling psychology at a large midwestern university and of licensed professional psychologists working at or 
consulting for the counseling center at the same university. There were 138 participants, and $74 \%$ were women. Thirty-four percent of the sample were first-year master's students, $22 \%$ were second-year master's students, $38 \%$ were postmaster's doctoral students, and $5 \%$ were professional psychologists. Of these participants, $19 \%$ had no clinical experience, $19 \%$ had less than 1 year of experience, $16 \%$ had 1 to 2 years of experience, $16 \%$ had 3 to 4 years of experience, $17 \%$ had 5 to 10 years of experience, $9 \%$ had 10 to 15 years of experience, and $4 \%$ had more than 15 years of clinical experience. Relatively few of those asked to participate in the study declined: The response rate was $92 \%$.

\section{Instruments}

The Counselor Self-Efficacy Scale (CSES) consists of 20 items regarding knowledge and skill competencies related to the practice of individual and group counseling and therapy. The development of the items was based on reviews of the literature regarding knowledge and skill competencies needed by counselors (e.g., Borders \& Leddick, 1987; Boylan, Malley, \& Scott, 1988). An attempt was made to write items that would comprehensively assess the skills normally used in the practice of counseling while excluding skills primarily associated with particular theoretical approaches (see Appendix). Agreement by all four of the authors of this study was needed for items to be included in the scale.

The instrument used a 5-point response scale corresponding to Liken-type scale responses indicating degree of agreement regarding respondents' confidence in their counseling abilities. One half of the items are worded negatively to help protect against acquiescent response bias, this requiring that responses to positively worded items $(1,2,5,7,8,13,15,16,18$, and 20$)$ be inversely recoded so that high scores correspond with high self-efficacy.

We addressed content-related validity evidence by asking expert judges to evaluate the CSES. Three licensed psychologists currently supervising trainees at a large midwestern university counseling center served as the expert judges. To allow for possible differences in theoretical orientation regarding the importance of particular skills to the practice of counseling and therapy, we established a criterion of agreement by two out of the three judges regarding the appropriateness of each of the items for measuring counselor self-efficacy for retaining items in the instrument. The inclusion criterion was met for all of the proposed items, and the judges were in unanimous agreement regarding 19 out of the 20 items.

The Serf-Efficacy Inventory (Friedlander \& Snyder, 1983) measures the same construct as the CSES and was used to examine the convergent construct-related validity of the CSES. It consists of 21 items covering five areas related to counselor performance: assessment (using various kinds of test and interview data), individual therapy (with persons having various categories of psychiatric diagnoses), group and family intervention, case management, and completion of academic requirements, The instrument uses a 10-point Likert-type response scale, and the items are written in the following format: "How confident are you in your ability to ... do individual counseling or therapy with individuals having personality disorders" or " . . make appropriate referrals?" The Cronbach alpha internal consistency correlation coefficient for the measure was found to be .93. We reported contentrelated validity evidence for the instrument and found that it helped predict expectations for type of supervision desired by trainees with varying levels of experience. 


\section{Procedure}

Signed informed consent forms were required of all of the study participants but were collected separately from the questionnaires to help protect the participants' anonymity and confidentiality. A short demographic questionnaire including items inquiring about level of training and amount of previous clinical experience was also administered to the participants.

\section{RESULTS}

An item analysis of the CSES items was conducted using a minimum item-total correlation of .35 as the criterion for retaining items in the instrument. All of the proposed items met this criterion. After this analysis was completed, the internal consistency of the instrument was computed by using the Cronbach alpha procedure and was found to be .91 .

We examined the temporal stability of the CSES using data from a subsample of 89 of the participants described earlier who were readministered the instrument after a 1-week interval. All levels of training were represented in the subsample, and clinical experience ranged from none to more than 15 years. The test-retest reliability coefficient for the total scale scores over the two test administrations was .85 .

We examined the convergent construct-related validity of the CSES by correlating scores obtained with this instrument to scores obtained with the Self-Efficacy Inventory (Friedlander \& Snyder, 1983). The convergent validity analysis was conducted using data from a subsample of 60 of the participants described earlier. All levels of graduate school students were represented in this subsample (no professional psychologists were included because the Self-Efficacy Inventory inquires about academic program requirements), and clinical experience ranged from none to more than 15 years. The correlation between the CSES and the Self-Efficacy Inventory was found to be high $(r=.83)$.

We examined the construct-related validity of the CSES by testing hypotheses based on both selfefficacy theory and counselor development models using data from all of the study participants. Experience with a particular activity generally raises one's self-efficacy expectations for engaging in that activity. Therefore, higher levels of counseling experience as measured by level of clinical training and experience were expected to correlate positively with CSES scores.

In a multiple regression of CSES scores with level of training and amount of clinical experience as the independent variables, the $F$ values were significant both for level of training, $F(1,135)=66.25, p<$ .0001 , and for amount of clinical experience, $F(2,134)=49.85, p<.0001$. Participants level of training and amount of clinical experience together accounted for a large proportion of the variance in CSES scores $(43 \% ; R=.65)$. Level of training accounted for slightly more of the variance $(18 \%)$ than did amount of clinical experience (14\%; partial $r s=.43$ and .38 , respectively). This pattern is also reflected in the correlation between CSES scores and level of training (.62) and the correlation between CSES scores and amount of clinical experience (.55); the correlation between level of training and amount of clinical experience was .48 .

Analyses of variance (ANOVAs) with Duncan's multiple comparisons procedure found four significantly different levels of training groups corresponding to first-year master's students, second-year master's students, postmaster's doctoral students, and professional psychologists, $F(3,134)=23,44, p<.0001$. 
The same statistical procedure found three significantly different clinical experience groups, $F(6,119)=$ $15.47, \mathrm{p}<.0001$ (see Table 1). Although only three significantly different groups emerged from this analysis, the mean scores for the seven experience levels clearly suggest a consistent trend toward greater counseling self-efficacy as measured by the CSES being associated with greater clinical experience.

Previous studies on counselor development have not controlled for part-time versus full-time experience when examining the relationship between clinical experience and counselor development. In this study, participants were asked if their clinical experience had been primarily full time or part time, but this additional data did not increase the variance explained in a multiple regression of CSES scores, and an ANOVA with part-time clinical experience counting for one half as much as full-time experience resulted in exactly the same pattern as the results of the previous analysis. That is, the noclinical experience group had significantly lower scores than the group with some through 4 years of estimated full-time experience, which was significantly lower than the group with 5 or more years of estimated full-time experience, $F(6,119)=12.68, p<.0001$.

\section{DISCUSSION}

Considerable empirical support was found for the CSES in terms of both reliability and validity. Internal consistency and test-retest coefficients were high, and the instrument correlated highly with a previously developed counseling self-efficacy scale. Evidence for the validity of the CSES was provided by tests of hypotheses based on self-efficacy theory and on models of counselor development, which found substantial correlations between CSES scores and level of training, as well as between CSES scores and amount of clinical experience.

The findings of this study not only suggest that the CSES may be a reliable and valid measure of counseling self-efficacy, but they also suggest that there are four groups of graduate students and professionals that differ significantly in terms of counseling self-efficacy. (In data not reported here, a fifth group of undergraduate juniors and seniors in interviewing courses was also identified as having significantly lower CSES scores than the beginning graduate students.) Part of the debate regarding the validity of models of counselor development has revolved around the paucity of empirical evidence for changes in counselor characteristics at different levels of training and clinical experience other than between beginning trainees and doctoral interns. Unlike previous studies examining counseling selfefficacy or counselor development generally, the four significantly different groups found here correspond roughly to the groups identified in stage models of counselor development, thus providing the clearest support for the validity of these models to date.

Also noteworthy was the finding that level of training accounted for slightly more of the variance in CSES scores than amount of clinical experience, suggesting that the extended graduate training of doctoral programs in applied psychology provides increases in professional self-efficacy and competence that cannot be gained solely through acquiring additional clinical experience with bachelor's- or master's-level training. In addition, an unexpected finding was that full-time clinical experience did not contribute more to explaining variance in CSES scores compared with part-time experience. 
Perhaps the primary limitation of the study reported here is the lack of behavioral observation to validate the CSES; research of this type could go a long way toward establishing the validity of both the CSES and developmental models of supervision. A second limitation concerns the representativeness of the participant sample: Few professional psychologists were included in the sample, all of the participants were recruited at one university, and all of the participants were associated with counseling psychology and not other mental health fields.

The present study also addresses only one aspect of counselor development. Although the training and clinical experience of the four groups of graduate students and psychologists identified earlier correspond roughly to the levels described in stage models of counselor development, these models suggest that there are many other specific changes associated with becoming a professional counselor or psychologist other than changes in clinical self-efficacy (e.g., changes in supervisee learning style [Fleming, 19531, dependency (Hogan, 1964], cognitive complexity [Blucher, 1983], self-awareness [Loganbill et al, 1983], motivation [Stoltenberg \& Delworth, 1987], predominant affect [Skovholt \& Ronnestad, 1992]). Although much additional research is needed to investigate the range and interaction of factors hypothesized to influence counselor and therapist development (see Bernard \& Goodyear [1992], Skorholt \& Ronnestad [1992], and Stoltenberg \& Delworth [1987] for a comprehensive discussion of these factors), the findings of the research reported here provide support for models of counselor development that they have not received before.

TABLE 1

CSES Scores for Participants With Various Levels of Training and Clinical Experience, With Multiple Comparisons Results

\begin{tabular}{|c|c|c|c|c|c|c|c|c|c|c|}
\hline \multirow[b]{2}{*}{ Group } & \multirow[b]{2}{*}{$n$} & \multirow{2}{*}{$\begin{array}{l}\text { Mean } \\
\text { Score }\end{array}$} & \multirow[b]{2}{*}{$S D$} & \multicolumn{7}{|c|}{ Group $^{a}$} \\
\hline & & & & 1 & 2 & 3 & 4 & 5 & & 7 \\
\hline \multicolumn{11}{|l|}{ Level of training } \\
\hline 1st year (master's) & 47 & 3.36 & 0.61 & & & & & & & \\
\hline 2nd year (master's) & 31 & 3.82 & 0.40 & * & & & & & & \\
\hline 3rd-6th year (doctoral) & 53 & 4.26 & 0.40 & * & * & & & & & \\
\hline Psychologist $^{b}$ & 7 & 4.71 & 0.13 & * & * & * & & & & \\
\hline \multicolumn{11}{|l|}{ Years of clinical experience } \\
\hline None & 24 & 3.28 & 0.54 & & & & & & & \\
\hline $0-1$ & 24 & 3.83 & 0.51 & $*$ & & & & & & \\
\hline $1-2$ & 20 & 3.85 & 0.38 & * & & & & & & \\
\hline $3-4$ & 20 & 3.96 & 0.46 & * & & & & & & \\
\hline $5-10$ & 2.1 & 4.35 & 0.40 & * & * & * & * & & & \\
\hline $10-15$ & 12 & 4.40 & 0.39 & * & * & * & * & & & \\
\hline 15 or more & 5 & 4.58 & 0.19 & * & * & * & * & & & \\
\hline
\end{tabular}

Note. CSES $=$ Counselor Self-Efficacy Scale.

${ }^{a}$ An asterisk denotes pairs of groups significantly different from each other at the $p<.05$ level using Duncan's multiple comparisons procedure. ${ }^{\mathrm{b}}$ This group consists of professional psychologists holding doctoral degrees.

TABLE 1 CSES Scores for Participants With Various Levels of Training and Clinical Experience, With Multiple Comparisons Results 


\begin{tabular}{|l|l|l|l|l|l|l|l|l|l|l|}
\hline Group & $n$ & $\begin{array}{l}\text { Mean } \\
\text { Score }\end{array}$ & $S D$ & 1 & 2 & 3 & 4 & 5 & 6 & 7 \\
\hline Level of training & & & & & & & & & & \\
\hline 1st year (master's) & 47 & 3.36 & 0.61 & & & & & & & \\
\hline 2nd year (master's) & 31 & 3.82 & 0.40 & $*$ & & & & & & \\
\hline 3rd-6th year (doctoral) & 53 & 4.26 & 0.40 & $*$ & $*$ & & & & & \\
\hline Psychologist & 7 & 4.71 & 0.13 & $*$ & $*$ & $*$ & & & & \\
\hline Years of clinical experience & & & & & & & & & & \\
\hline None & 24 & 3.28 & 0.54 & & & & & & & \\
\hline $0-1$ & 24 & 3.83 & 0.51 & $*$ & & & & & & \\
\hline $1-2$ & 20 & 3.85 & 0.38 & $*$ & & & & & & \\
\hline $3-4$ & 20 & 3.96 & 0.46 & $*$ & & & & & & \\
\hline $5-10$ & 21 & 4.35 & 0.40 & $*$ & $*$ & $*$ & $*$ & & & \\
\hline $10-15$ & 12 & 4.40 & 0.39 & $*$ & $*$ & $*$ & $*$ & & & \\
\hline 15 or more & 5 & 4.58 & 0.19 & $*$ & $*$ & $*$ & $*$ & & & \\
\hline
\end{tabular}

Note. CSES = Counselor Self-Efficacy Scale.

aAn asterisk denotes pairs of groups significantly different from each other at the $p<.05$ level using Duncan's multiple comparisons procedure. $\mathrm{s}$ This group consists of professional psychologists holding doctoral degrees.

\section{REFERENCES}

Bandura, A. (1977). Toward a unifying theory of behavioral change. Psychological Review, 84, 191-215.

Bandura, A. (1982). Self-efficacy mechanisms and human agency. American Psychologist, 37, 122-147.

Bandura, A. (1986). The explanatory and predictive score of self-efficacy theory. Journal of Social and Clinical Psychology, 4, 359-373.

Bandura, A. (1989). Human agency in social cognitive theory. American Psychologist, 44, 1175-1184.

Bernard, J. M., \& Goodyear, R. K. (1992). Fundamentals of clinical supervision. Boston: Allyn \& Bacon.

Blocher, D, H. (1983). Toward a cognitive developmental approach to counseling supervision. The Counseling Psychologist, 11, 27-34.

Borders, L. D. (1989). A pragmatic agenda for developmental supervision research. Counselor Education and Supervision, 29, 16-24.

Borders, L. D., \& Leddick, G. R. (1987). Handbook of counseling supervision. Alexandria, VA: Association for Counselor Education and Supervision.

Boylan, J. C., Malley, P. B., \& Scott, J. (1988). Practicum and internship: Textbook for counseling and psychotherapy. Muncie, IN: Accelerated Development.

Fleming, J. (1953). The role of supervision in psychiatric training. Bulletin of the Menninger Clinic, 17, 157-159.

Friedlander, M. L., Keller, K. E., Peca-Baker, T. A., \& Olk, M. E. (1986). Effects of role conflict on counselor trainees self-statements, anxiety level, and performance. Journal of Counseling Psychology, 33, 73-77.

Friedlander, M. L., \& Snyder, J. (1983). Trainees' expectations for the supervisory process: Testing a developmental model. Counselor Education and Supervision. 22, 343-348.

Grater, H. A. (1985). Stages in psychotherapy supervision: From therapy skills to skilled therapist. Professional Psychology: Research and Practice. 16, 605-610.

Heppner, P. P., \& Roehlke, H. J. (1984). Differences among supervisees at different levels of training: Implications for a developmental model of supervision. Journal of Counseling Psychology, 30, 252-262.

Hess, A. K. (1987). Psychotherapy supervision: Stages, Buber and a theory of relationship. Professional Psychology: Research and Practice, 18, 251-259.

Hogan, R. A. (1964). Issues and approaches in supervision. Psychotherapy: Theory, Research and Practice, 1, 139141. 
Holloway, E. L. (1987). Developmental models of supervision: Is it development? Professional Psychology: Research and Practice, 18, 209-216.

Johnson, E., Baker, S. B., Kopala, M., Kiselica, M. S., \& Thompson, E. C. (1989). Counseling self-efficacy and counseling competence in prepracticum training. Counselor Education and Supervision, 28, 205-218.

Larson, L. M, Suzuki, L. A., Gillespie, K. N., Potenza, M. T, Bechtel, M. A., \& Toulouse, A. L. (1992). Development and validation of the counseling self-estimate inventory. Journal of Counseling Psychology, 39. 105-120.

Littrell, J. M., Lee-Borden, N, \& Lorenz, J. (1979). Developmental framework for counseling supervision. Counselor Education and Supervision. 19, 129-136.

Loganbill, C., Hardy, E., \& Delworth, U. (1982). Supervision: A conceptual model. The Counseling Psychologist, 10, 3-42.

Miars, R. D., Tracey, T. J., Ray, P. B., Cornfeld, J. L., O'Farrell, M., \& Gelso, C. J. (1983). Variation in supervision process across trainee experience levels. Journal of Counseling Psychology, 30, 403-412.

Orlinsky, D. E., \& Howard, K. I. (1986). Process and outcome in psychotherapy. In S. L. Garfield \& A. E. Bergin (Eds.), Handbook of psychotherapy and behavior change (pp. 311-384). New York: Wiley.

Reising, G. N., \& Daniels, M. H. (1983). A study of Hogan's model of counselor development and supervision. Journal of Counseling Psychology, 30, 235-244.

Russell, R. K., \& Petrie, T. (1994). Issues in training effective supervisors. Applied and Preventive Psychology, 3, 27-42.

Sipps, G. J., Sugden, G. J., \& Favier, C. M. (1988). Counselor training level and verbal response type: Their relationship to efficacy and outcome expectations. Journal of Counseling Psychology, 35, 397-401.

Skovholt, T. M., \& Runnested, M. H. (1992). The evolving professional self New York: Wiley.

Stoltenberg, C. D. (1981). Approaching supervision from a developmental perspective: The counselor complexity model. Journal of Counseling Psychology, 28, 59-65.

Stoltenberg, C. D., \& Delworth, U. (1987). Supervising counselors and therapists: A developmental approach. San Francisco: Jossey-Bass.

Stoltenberg, C. D., \& Delworth, U. (1988). Developmental models of supervision: It is development--Response to Holloway. Professional Psychology: Research and Practice, 19, 134-137.

Tracey, T. J., Hays, K. A., Malone, J., \& Herman, B. (1988). Changes in counselor response as a function of experience. Journal of Counseling Psychology, 35, 119-126.

Wiley, M, \& Ray, P. B. (1986). Counseling supervision by developmental level. Journal of Counseling Psychology, 33, 439445.

Worthington, E. L. (1984). An empirical investigation of supervision of counselors as they gain experience. Journal of Counseling Psychology, 31, 63-75.

Worthington, E. L., \& Stern, A. (1985). The effects of supervisor and supervisee degree level and gender on the supervisory relationship. Journal of Counseling Psychology, 32, 252-262.

\section{APPENDIX The Counselor Self-Efficacy Scale Items}

1. My knowledge of personality development is adequate for counseling effectively.

2. My knowledge of ethical issues related to counseling is adequate for me to perform professionally.

3. My knowledge of behavior change principles is not adequate.

4. I am not able to perform psychological assessment to professional standards.

5. I am able to recognize the major psychiatric conditions.

6. My knowledge regarding crisis intervention is not adequate.

7. I am able to effectively develop therapeutic relationships with clients.

8. I can effectively facilitate client self-exploration.

9. I am not able to accurately identify client affect.

10. I cannot discriminate between meaningful and irrelevant client data.

11. I am not able to accurately identify my own emotional reactions to clients,

12. I am not able to conceptualize client cases to form clinical hypotheses, 
13. I can effectively facilitate appropriate goal development with clients.

14. I am not able to apply behavior change skills effectively,

15. I am able to keep my personal issues from negatively affecting my counseling.

16. I am familiar with the advantages and disadvantages of group counseling as a form of intervention.

17. My knowledge of the principles of group dynamics is not adequate.

18. I am able to recognize the facilitative and debilitative behaviors of group members.

19. I am not familiar with the ethical and professional issues specific to group work.

20. I can function effectively as a group leader/facilitator.

Note. Response options range from 1 to 5 (agree strongly, agree moderately, neutral/uncertain, disagree moderately, disagree strongly). All negatively worded items are recoded so that high scores indicate high self-efficacy.

By Timothy P. Melchert, Victoria L. Hays, Lynn M. Wiljanen, and Ann K. Kolocek

Timothy P. Melchert is an assistant professor in the Department of Psychology at Texas Tech University, Victoria L. Hays is a psychologist at University of Michigan Counseling and Psychological Services. Lynn M. Wiljanen is an assistant director in the Career Center at Colorado State University. Ann K. Kolocek is a psychologist in private practice in Beaver Dam, Wisconsin. Correspondence regarding this article should be sent to Timothy P. Melchert, Department of Psychology, Texas Tech University, Box 42051. Lubbock, TX 79409-2051.

Copyright of Journal of Counseling \& Development is the property of Wiley-Blackwell and its content may not be copied or emailed to multiple sites or posted to a listserv without the copyright holder's express written permission. However, users may print, download, or email articles for individual use. 